\title{
ERCP komplikasyonları; sıklığı, etkileyen faktörler ve yönetimi
}

\author{
Endoscopic retrograde cholangiopancreatography: frequency, contributing factors and management
}

Nurettin TUNÇ, Salih KILIÇ, Abdurahman ŞAHIN, Ulvi DEMIREL, Orhan K. POYRAZOĞLU, İbrahim H. BAHÇECIOĞLU, Mehmet YALNIZ

Fırat Üniversitesi Tip Fakültesi, Iç Hastalılanı Anabilim Dalı, Gastroenteroloji Bilim Dalı, Elazığ

Giriş ve Amaç: Safra yolları ve pankreas hastalıklarının tanı ve tedavisinde yaygın olarak kullanılan bir yöntem olan endoskopik retrograt kolanjiopankreatikografi ile ciddi komplikasyonlar bildirilmiştir. Bu komplikasyonlar endoskopik retrograt kolanjiopankreatikografi işlemine bağlı sfinkterotomi yerinden kanama, pankreatit, kolanjit, perforasyon ile kardiyopulmoner komplikasyonlar (hipoksi, hipotansiyon ve aritmi gibi) ve ölümdür. Bu çalışmadaki amacımız endoskopik retrograt kolanjiopankreatikografi işlemi ile kompliklasyon gelişen hastalarda risk faktörlerini saptamak ve bu hastalarda uygun tanısal ve terapötik yaklaşımı belirlemektir. Gereç ve Yöntem: 2016 yılı içinde endoskopik retrograt kolanjiopankreatikografi işlemi yapılan 487 hastanin verileri retrospektif olarak elde edildi. Bulgular: Endoskopik retrograt kolanjiopankreatikografi ișlemi uygulanan 487 vakanın 304'ü $(\% 62,4)$ kadın, 183'ü $(\% 37,6)$ erkekti. Ortalama yaş 61,53 (min-maks: 18-99) yl idi. Post-endoskopik retrograt kolanjiopankreatikografi komplikasyonlarn 53 (\% 10,8) vakada görülmüş; 37'si $(\% 7,6)$ pankreatit, 15'i $(\% 3,1)$ kanama, 1'i $(\% 0,2)$ duodenum perforasyonu olarak raporlanmıștı. Iğne uçlu sfinkterotom ile ön kesi yapilan 2/67 (\%2,9) vakada post-endoskopik retrograt kolanjiopankreatikografi pankreatiti gelişmiş olmasına karşı ön kesi yapılmayan 65/420 $(\% 8,33)$ vakada post-endoskopik retrograt kolanjiopankreatikografi pankreatiti gelişmişti. Post-endoskopik retrograt kolanjiopankreatikografi pankreatiti iğne uçlu sfinkterotom ile ön kesi yapılanlarda daha az oranda görülmekle birlikte istatistiksel olarak anlamlı değildi ( $p: 0,127)$. Yapılan endoskopik retrograt kolanjiopankreatikografinin kaçıncı endoskopik retrograt kolanjiopankreatikografi işlemi olduğu ve post-endoskopik retrograt kolanjiopankreatikografi pankreatiti ilişkisi karșılaștırıldığında post-endoskopik retrograt kolanjiopankreatikografi pankreatiti gelişimi ilk kez endoskopik retrograt kolanjiopankreatikografi yapılanlarda (\%91) anlamlı olarak daha sık gözlenmiş (p: 0,041), post endoskopik retrograt kolanjiopankreatikograf komplikasyon olarak mortalite hiç izlenmemişti. Sonuç: Post endoskopik retrograt kolanjiopankreatikografi pankreatiti endoskopik retrograt kolanjiopankreatikografinin en sık komplikasyonudur. Endoskopik retrograt kolanjiopankreatikografi ile ciddi komplikasyonlar görülebilmesine rağmen uygun endikasyonda endoskopik retrograt kolanjiopankreatikografi yapılması ve oluşan komplikasyonların erken tanınması morbidite ve mortalitenin önlenmesinde en önemli adımdır.

Anahtar kelimeler: Post endoskopik retrograt kolanjiopankreatikografi komplikasyonlar, pankreatit

\section{GİRIS}

Endoskopik retrograt kolanjiopankreatikografi (ERCP) safra yolları ve pankreas hastalıklarının tanı ve tedavisinde yaygın olarak kullanılan bir yöntemdir (1). ERCP'nin invaziv bir girişim olması potansiyel komplikasyonlara ait riskleri de birlikte getirmektedir (1). Son yllarda multidedektör bilgisayarlı tomografik kolanjiografi (MDBT-kolanjiografi), magnetik re-
Background and Aims: Serious complications have been reported with endoscopic retrograde cholangiopancreatography, a widely used method for the diagnosis and treatment of bile duct and pancreatic diseases. These complications include hemorrhage from the sphincterotomy site due to the endoscopic retrograde cholangiopancreatography procedure; pancreatitis; cholangitis; cardiopulmonary complications such as perforation, hypoxia, and hypotension, arrhythmia; and death. Our aim in this study is to determine the risk factors in patients with complications of the endoscopic retrograde cholangiopancreatography procedure and to determine the appropriate diagnostic and therapeutic approach in these patients. Materials and Methods: Data on 487 patients undergoing endoscopic retrograde cholangiopancreatography in 2016 were retrospectively reviewed. Results: A total of 487 patients underwent endoscopic retrograde cholangiopancreatography, 304 (62.4\%) women and $183(37.6 \%)$ men. The mean age was 61.53 (range: 1899) years. Post-endoscopic retrograde cholangiopancreatography complications occurred in $53(10.8 \%)$ patients; 37 (7.6\%) reported pancreatitis; 15 (3.1\%), bleeding; and 1 (0.2\%), duodenal perforation. Post-endoscopic retrograde cholangiopancreatography improved in 2/67 (2.9\%) cases with needle knife pre-cut sphincterotomy and did not develop in cases of standard sphincterotomy 65/420 (8.33\%). Post- endoscopic retrograde cholangiopancreatography was less frequent in pre-cut sphincterotomy constructs, but the difference was not statistically significant $(p=0.127)$. When the number of endoscopic retrograde cholangiopancreatography and post-ERCP cases who developed pancreatitis was compared, post-endoscopic retrograde cholangiopancreatography pancreatitis was significantly more frequent for the first time endoscopic retrograde cholangiopancreatography applied (91\%) ( $p=0.041$ ). Mortality was not observed in post-ERCP pancreatitis. Conclusion: Post-endoscopic retrograde cholangiopancreatography pancreatitis is the most common complication of endoscopic retrograde cholangiopancreatography. Although serious complications can be seen with endoscopic retrograde cholangiopancreatography, the technique should be used with the appropriate indications, and early identification of complications is the most important step in preventing morbidity and mortality.

Key words: Post-endoscopic retrograde cholangiopancreatography complications, pancreatitis

zonans kolanjiopankreatografi (MRCP) ve endoskopik ultrasonografi (EUS) gibi görüntüleme tekniklerinin gelişmesi ile tanısal ERCP giderek daha az kullanılır olmuştur (2). Tanısal ERCP, ancak MRCP gibi görüntüleme tekniklerinde anormal görüntü yokluğunda pankreatiko-biliyer hastalık şüphesinde yapilmaktadır $(3,4)$. 
ERCP güvenilir ve etkili bir tedavi yöntemi olarak tanımlanmakla birlikte $(3,4)$ literatürde \%10'lara ulaşan komplikasyonlar bildirilmiştir. Bu komplikasyonların \%1-2'si ciddi komplikasyonlar olup \% l'in altında ölüm oranları raporlanmıştır (5). ERCP işlemine bağlı sfinkterotomi yerinden kanama, post-ERCP pankreatit (PEP), kolanjit, perforasyon ve kardiyopulmoner (hipoksi, hipotansiyon ve aritmi) komplikasyonlar ile ölüm görülebilir (1). Bu nedenle ERCP işleminin güvenilirliğini arttırmak için ERCP komplikasyonlarının risk faktörlerini çok iyi belirlemek gerekmektedir (6).

Bu çalışmadaki amacımız ERCP işlemi ile komplikasyon gelişen hastalarda risk faktörlerini saptamakla birlikte uygun tanısal ve terapötik yaklaşımı belirlemektir.

\section{GEREC ve YÖNTEM}

Fırat Üniversitesi Tıp Fakültesi Gastroenteroloji Bilim Dalı Endoskopi ünitesinde 2016 yllı içinde ERCP işlemi yapılan 487 hastanın verileri retrospektif olarak incelendi. Hastaların yaş, cinsiyet gibi demografik verileri, laboratuvar ve endoskopik verileri hastane bilgi işlem veri tabanından elde edildi. Raporlarda ERCP endikasyonu, kaçıncı ERCP olduğu, ERCP'de yapılan işlemler ve işlem esnasında komplikasyon varlığı kaydedildi.

Post-ERCP kanama, pankreatit, perforasyon, enfeksiyon komplikasyonları ve bu komplikasyonların nasıl yönetildiği hasta dosyalarından elde edildi. Komplikasyonların tanımı ve derecelendirmesi Amerikan Gastrointestinal Endoskopi Derneği (ASGE-American Society of Gastrointestinal Endoscopy) kriterlerine göre yapıldı (7). Yeni başlayan karın ağrısı ve amilaz’ın 3 kattan fazla yüksekliği pankreatit olarak tanımlandı. Amilaz düzeyi normalin üst sınırının 3 katından az yükselmesi ve eşlik eden karın ağrısı olmaması hiperamilazemi olarak tanımlandı (8). Klinik olarak kanama bulgusu, hemoglobinde $3 \mathrm{~g} / \mathrm{dl}$ düşüş veya kan transfüzyonu ihtiyacı olması kanama olarak, ateş ve sarılık varlığında kolanjit, direkt karın grafisi, bilgisayarlı tomografide serbest hava görüldü ise perforasyon olarak değerlendirildi (7). PEP tanısı ve şiddeti uluslararası standart kriterlere göre belirlendi (8). Hafif pankreatit; işlemden 24 saat sonra amilaz düzeyinde 3 kat veya daha fazla yükseklik, hastanede yatma gerekliliği ya da planlanan yatış süresinin 2-3 gün uzaması, orta derecede pankreatit; hastanede planlanan yatıs süresinin 4-10 gün uzaması, ciddi pankreatit; yatıs ihtiyacının 10 günden fazla olması, flegmon, apse, psödokist olması, cerrahi veya perkütan müdahale ihtiyacının olması olarak tanımlandı (8).

\section{İstatistik}

Tüm istatistiksel analizler, SPSS 22.0 yazılımı (SPSS Inc., Chicago, IL, Amerika Birleşik Devletleri) kullanılarak gerçekleştirildi. Kategorik verilerin analizi için bir $\chi 2$ testi veya Fisher'in exact testi kullanıldı. Tüm hasta özellikleri, ortalama \pm SD (mi- nimum-maksimum) veya uygun olduğunda yüzdeler şeklinde ifade edilmiştir. Tüm testleri istatistiksel anlamlllık $\mathrm{p}<0.05$ olarak belirlendi.

\section{BULGULAR}

ERCP işlemi uygulanan 487 vakanın 304'ü $(\% 62,4)$ kadın, 183'ü $(\% 37,6)$ erkekti. Ortalama yaş 61,53 (min-mak: 1899) yıl idi. ERCP yapılan vakaların endikasyonlarının 421'i $(\% 86,4)$ koledokolitiazis veya kolestatik enzim artışı, 36's1 $(\% 7,4)$ biliyer pankreatit, 12'si (\%2,5) kolanjit, 14'ü (\%2,9) malignite (koledok-pankreas kitle), 3’ü $(\% 0,6)$ safra kaçağ1 ve l’i $(\% 0,2)$ kist hidatik idi. Toplam 487 vakaya 623 işlem yapılmıs, vakaların 437 'sine $(\% 89,7)$ sfinkterotomi ve taş ekstraksiyonu, $75^{\prime}$ ine $(\% 15,4)$ stent yerleştirilmesi, 24'üne $(\% 4,9)$ balon dilatasyonu, 14 'üne $(\% 2,9)$ mekanik litotripsi, 4'üne nazobiliyer dren yerleștirilmesi, l'ine buji dilatasyonu uygulanmıştı (Tablo 1).

Vakaların 67'sine $(\% 13,8)$ iğne uçlu sfinkterotomla ön kesi (ortalama 5 kez kanülasyon denendikten veya 7-8 dakikalık süreden sonra) yapılmış ve 23 'ünde $(\% 4,7)$ işlem yapılamamıştı, işlem başarısı 465'ti $(\% 95,3)$. ERCP başarısız olan vakaların 9'unda $(\% 39,1)$ cerrahi nedeniyle değişmiş anatomik yapı (Billroth II hepatikoduodenostomi gibi) mevcuttu, 4'ünde $(\% 17,4)$ hasta işlemi tolere edememiş, 5 'inde $(\% 21,7)$ bulbusa bası veya deforme bulbus-pilor, 2'sinde $(\% 8,7)$ duodenum infiltrasyonu, l'inde $(\% 4,3)$ papil tümörü, l'inde $(\% 4,3)$ duodenal ülser ve l'inde $(\% 4,3)$ duodenal perforasyon mevcuttu (Tablo 1). Bu vakalarn 2'sinde ikinci ERCP ile başarı sağlanmış, 3'üne cerrahi tedavi, 2'sine onkolojik tedavi ve 8'ine perkütan transhepatik kolanjiografi (PTK) uygulanmıştı.

ERCP ve post-ERCP komplikasyonlar $53(\% 10,8)$ vakada görülmüştü. Bunların 37'si $(\% 7,6)$ pankreatit, 28'i $(\% 5,7)$ post ERCP hiperamilazemi, 15'i $(\% 3,1)$ kanama, l'i $(\% 0,2)$ duodenum perforasyonu olarak raporlanmıştı. Bu komplikasyonlar vakaların 381'inde $(\% 78,2)$ birinci, 67 'sinde $(\% 13,8)$ ikinci ve 39'unda (\%8) üçüncü ve üzeri ERCP işlemi esnasında gözlenmişti (Tablo 1).

Komplikasyonlardan perforasyon gelişen hasta cerrahi müdahale ile tedavi edilmişti. Kanama gelişen vakaların sadece birinde transfüzyon ihtiyacı, diğer 14 vakada minör kanama olup 3'ü heater-prob ile diğerleri takip ve konservatif (proton pompası inhibitörü infüzyonu, sıvı replasmanı) yöntemlerle düzelmişti. Pankreatitli hastaların tümünün kliniği hafif seyretmiş ve hastaların hiçbirinde şiddetli pankreatit veya ölüm gelişmemişti.

PEP $37(\% 7,6)$ vakada, post-ERCP hiperamilazemi $28(\% 5,7)$ vakada gözlenmiști. PEP gelişen $37(\% 7,6)$ vakanın yaş ortalaması PEP gelişmeyen vakalarla karşılaştıııldığında istatistiksel olarak anlamlı olmasa da daha küçüktü $(59,32$ yıl'a karşı 


\section{Tablo 1. ERCP vakalarının genel özellikleri}

\begin{tabular}{|c|c|c|}
\hline Cins (K/E) n & & $304 / 183$ \\
\hline Yaş (ortalama-yıl) & & 61,53 \\
\hline ERCP tanı n (\%) & $\begin{array}{l}\text { Koledokolitiazis } \\
\text { Kolestatik enzim artışı } \\
\text { Biliyer pankreatit } \\
\text { Kolanjit } \\
\text { Malignite } \\
\text { Safra kaçağı } \\
\text { Kist hidatik }\end{array}$ & $\begin{array}{l}164(33,7) \\
257(52,8) \\
36(7,4) \\
12(2,5) \\
14(2,9) \\
3(0,6) \\
1(0,2)\end{array}$ \\
\hline Komplikasyon n (\%) & $\begin{array}{l}\text { Toplam } \\
\text { PEP } \\
\text { Kanama } \\
\text { Perforasyon }\end{array}$ & $\begin{array}{l}53(10,8) \\
37(7,6) \\
15(3,1) \\
1(0,1)\end{array}$ \\
\hline Yapılan işlemler n (\%) & $\begin{array}{l}\text { İslem başarısı } \\
\text { Sfinkerotomi/taş ekstraksiyonu } \\
\text { Stent yerleştirilmesi } \\
\text { Balon dilatasyonu } \\
\text { Buji dilatasyonu } \\
\text { Mekanik litotripsi } \\
\text { Ön kesi }\end{array}$ & $\begin{array}{l}464(95,3) \\
437(89,7) \\
75(15,4) \\
24(4,9) \\
1(0,2) \\
14(2,9) \\
67(13,8)\end{array}$ \\
\hline İşlem yapılamayan n (\%) & $\begin{array}{l}\text { Toplam } \\
\text { Cerrahi ile değişmiş anatomi (Billroth II vb) } \\
\text { Bulbus-pilor deformasyonu basısı } \\
\text { Hasta intoleransı (A/nbz O2 satürasyonu) } \\
\text { Duodenum malign infiltrasyon } \\
\text { Duodenal ülser } \\
\text { Papil tm } \\
\text { Perforasyon }\end{array}$ & $\begin{array}{l}23(4,7) \\
9(39,1) \\
5(21,7) \\
4(17,4) \\
2(8,7) \\
1(4,3) \\
1(4,3) \\
1(4,3)\end{array}$ \\
\hline
\end{tabular}

ERCP: Endoskopik retrograt kolanjiopankreatikografi. PEP: Post-ERCP pankreatit.

61,9 yll). PEP gelişenlerin 28'i (\%75,7) kadın, 9’u (\%24,3) erkekti (p: 0,83) (Tablo 2). Yaş dağılımları ve PEP gelişimi arasinda (<65 n: 22, 65-80 n: 11, >80 üstü n: 4) anlamlı bir

\section{Tablo 2. PEP gelişen hastalarm genel özellikleri}

\begin{tabular}{|l|l|l|l|}
\hline & PEP & PEP - & P değeri \\
\hline Yaş (ort-yıl) & 59,32 & 61,9 & $>0,05$ \\
\hline Cins (K/E) & $28 / 9$ & $276 / 174$ & 0,083 \\
\hline Ön kesi (var/yok) & $2 / 35$ & $65 / 450$ & 0,127 \\
\hline Kaçıncı ERCP n (\%) & $\begin{array}{l}\text { Ilk ERCP } \\
\text { Ilkinci ve üzeri } \\
\text { ERCP }\end{array}$ & $34(91,9)$ & 0,46 \\
\hline
\end{tabular}

ERCP: Endoskopik retrograt kolanjiopankreatikografi. PEP: Post-ERCP pankreatit. fark yoktu (p: 0,41). PEP gelişen vakaların 35'inde $(\% 94,5)$ koledokolitiazis ve kolestatik enzim artışı, l'inde $(\% 2,7)$ malignite, l'inde $(\% 2,7)$ safra kaçağı ön tanısı ile işlem yapılmıştı. Vakaların 4'üne $(\% 11,4)$ koledok stenti yerleştirilmiş (p: 0,429), 3'üne $(\% 8,6)$ balon dilatasyonu (p: 0,345), birer vakaya buji dilatasyon ve mekanik litoripsi uygulanmış ve istatistiksel fark bulunmamıştı.

PEP vakalarının 2/67'si $(\% 2,9)$ iğne uçlu sfinkterotomla ön kesi, 35/420'si $(\% 8,33)$ standart sfinkterotom ile selektif kanülasyon sonrası gelişmişti. PEP ön kesi yapılanlarda daha az sıklıkta görülmekle birlikte istatistiksel anlamlı değildi (p: 0,127). ERCP'nin kaçıncı ERCP işlemi olduğu ve PEP gelişimi açısından karşılaştırıldığında PEP gelişen vakaların 34/37'si $(\% 91,9)$ birinci ERCP işlemi uygulanan, 3/37'si $(\% 8,1)$ ikinci 
ve üstü tekrarlayan ERCP işlemi uygulananlar arasında gelişmiş idi (p: 0,041) (Tablo 2). PEP gelişimi ilk ERCP yapılanlarda anlamlı olarak daha sık gözlenmektedir.

\section{TARTISSMA}

ERCP işleminin güvenilirliğini arttırmak için ERCP komplikasyonları açısından risk faktörlerini çok iyi belirlemek gerekmektedir.

Cem OK. ve arkadaşlarının 1155 hastayı dahil ettiği çalışmada en sık ERCP endikasyonları $(\% 86,4)$ bizim çalışmamızla benzer olarak $(\% 81,7)$ kolestatik enzim yüksekliği araştırılması ve diğer görüntüleme yöntemleriyle koledok taşı saptanması idi (1). Atamanalp ve arkadaşlarının 3.136 vakalık çalışmasında, 3.136 hastanın 2.965'ine (\%94,5) başarılı kanülasyon yapılmıs 465 (\%14,8) ön kesi yapılmış, 171'inde $(\% 5,5)$ işlem yapılamamıştı $(9)$. Çalışmamızda benzer şekilde vakaların 67 'sine $(\% 13,8)$ ön kesi yapılmış ve 23 'ünde $(\% 4,7)$ işlem yapılamamıştı, işlem başarısı \%95,3 ile benzerdi.

Yapılan çalışmalarda başarısız kanülasyonun en sık nedeni hasta intoleransı \%31 ve pilor ve duodenum darllğı \%21,6 (9), geçirilmiş cerrahi (mide ve Bilroth II) \%20 (10), periampuller divertikül veya ampulla pozisyon anomalisi \%67,2 (1) iken çalışmamızda cerrahi nedeniyle değişmiş anatomik yapı $9 / 23(\% 39,1)$ ve bulbus deformasyonu-basisı $5 / 23(\% 21,7)$ en sik nedendi.

ERCP sonrası komplikasyon oranları \%3,8 ile \%20,8 arasında değişmektedir $(9,11)$. Bizim çalışmamızda da komplikasyon oranı \%10,8 ile literatür ile uyumlu idi. Cotton PB. ve arkadaşları 11.497 işlemi inceledikleri çalışmalarında komplikasyon oranını \% 4,0 ve PEP oranını \%2,6 saptamıs (12). Imbeth AP. ve arkadaşlarının 96 vakayı inceledikleri diğer bir çalışmada toplam \%20,8 komplikasyon gelișmiș; en sık \%11,5 ile pankreatit görülmüş ve ölüm oranı $\% 2,1$ saptanmış (11). Çalışmamıza 487 vaka dahil edilmiş, komplikasyon $(\% 10,8)$ ve PEP $(\% 7,6)$ oranları bu çalışmadan düşük olup ölüm hiç görülmemişti.

ERCP işleminin güvenilirliğinin 80 yaş üstü ve altı hastalarda değerlendirildiği bir çalışmada işlem başarısı ve komplikasyon oranları açısından gruplar arasında fark saptanmamışıtı (13). 90 yaş üstü ve 70-90 yaş arası hastalarda ERCP işlemi karşılaştırılmış ve 90 yaş üstü ve altı grupta ERCP sonrası erken komplikasyon oranları benzer saptanmıştı (14). Çalışmamızda literatürle uyumlu olarak 65 yaş altı, 65-80 yaş arası ve 80 yaş üzeri olan hastalarda post-ERCP komplikasyon (p: $0,197)$ ve PEP gelişimi (p: 0,41) açısından anlaml fark saptanmadı. Yaş ve PEP ilişkisinin incelendiği 3.142 vakalık çalışmada (15) 45-65 yaş, 65-80 yaş ve 80 yaş üstü hastalarda, çalışmamızla uyumlu olarak, PEP komlikasyonu açısından anlamlı fark yoktu.

PEP riski genç yaş (55 yaş altı) ve kadın cinsiyette artmaktadır (16). Literatür ile uyumlu olarak çalısmamızda PEP kadınlarda daha sık (p: 0,083) ve daha genç yaşta $(59,32$ yll'a karşı 61.7 yll) görülme eğiliminde olmakla birlikte istatistiksel olarak anlamlı değildi.

PEP riski iğne uçlu sfinkterotomla ön kesi ve pankreatik sfinkterotomi ile artmaktadır $(16,17)$. Ön kesi yapılan 118 vakada pankreatit gelişme riski yüksek bulunmuş (\%6,3'e karşı \%12,7) ancak bağımsız bir risk faktörü olmadığı saptanmıştır (16). Pankreatik kanala proflaktik stent takılması PEP riskini \%13,1'den \%5,8'e indirir $(18,19)$. Yüksek riskli hastalarda PEP'i önleme açısından erken ön kesi ile pankreas kanalına stent yerleştirilmesi işlemlerinin karşılaştıııldığı 101 hastanın dahil edildiği bir çalışmada erken ön kesi yapılanlarda PEP risk artışı bulunmadığı saptanmıştır (20). Çalışmamizda PEP ön kesi yapilanlarda daha az oranda 2/37 (\%2,9'e karşı \% 8,33) gelişmişti (p: 0,127). Yüksek riskli hastalarda ön kesi PEP'ten koruyucu olarak erken dönemde yapilmalıdır. Iğne uçlu sfikterotomla ön kesinin PEP'ten koruyuculuğunu göstermek için daha yüksek sayıda vakanın dahil edildiği prospektif çalışmalarla ihtiyaç vardır.

PEP vakalarının 34/37'si $(\% 91,9)$ ilk ERCP işlemi esnasında, 3/37'si $(\% 8,1)$ ise ikinci ve daha sonraki ERCP seansları esnasinda oluşmuştu (p: 0,041). PEP gelişimi ilk ERCP yapılanlarda anlamlı olarak daha sık gözlenmektedir. llk ERCP işlemi PEP için risk faktörü olarak düşünülmelidir.

Post-ERCP pankreatit en sık ERCP komplikasyonudur. ERCP ile ciddi komplikasyonlar görülebilmesine rağmen uygun endikasyonda ERCP yapılması ve oluşan komplikasyonların erken tanınması morbidite ve mortalitenin önlenmesinde en önemli adımdır.

\section{KAYNAKLAR}

1. Kıraç CO, Asıl M, Demir A. 4 yıllık endoskopik retrograd kolanjiopankreatografi vakalarımızın retrospektif değerlendirilmesi. Genel Tıp Derg 2016;26:53-7.

2. Kondo S, Isayama H, Akahane M, et al. Detection of common bile duct stones: comparison between endoscopic ultrasonography, magnetic resonance cholangiography, and helical-computed-tomographic cholangiography. Eur J Radiol 2005;54:271-5.

3. Huang LY, Liu YX, Wu CR, et al. Application of endoscopic retrograde cholangiopancreatography in biliarypancreatic diseases. Chinese Med J 2009; 122:2967-72

4. Sakai Y, Tsuyuguchi T, Ishihara T, et al. Is ERCP really necessary in case of suspected spontaneous passage of bile duct stones? World J Gastroenterol 2009; 15:3283-7. 
5. Andriulli A, Loperfido S, Napolitano G, et al. Incidence rates of post-ERCP complications: a systematic survey of prospective studies. Am J Gastroenterol 2007;102:1781-8.

6. Parvesh Kumar J, Vinay BN. Indications and complications of endoscopic retrograde cholangiopancreatography procedures in a tertiary care centre. Int J Adv Med 2016;3:838-41.

7. Cotton P, Williams C. ERCP and Therapy. Risks and Indications. In Cotton P, Williams C, editors. Practical Gastrointestyinal Endoscopy. 4th ed. Oxford: Blackwell Science; 1996;186.

8. Cotton PB, Lehman G, Vennes J, et al. Endoscopic sphincterotomy complications and their management: an attempt at consensus. Gastrointest Endosc 1991;37:383-93.

9. Atamanalp SS, Ylldırgan MI, Kantarcı A. Endoscopic retrograde cholangiopancreatography (ERCP): outcomes of 3136 cases over 10 years. Turk J Med Sci 2011;41:615-21.

10. Ülkü S, Ibrahim G, Altuğ Ş. Terapotik ERCP komplikasyonlanı için risk faktörleri: Tek merkezli prospektif çalışma. Akademik Gastroenteroloji Dergisi, 2006;5:163-8.

11. Imbeth AP, Guzman LI, Julliao H, Salej J, Galvan C. Complications and risk factors in patients undergoing endoscopic retrograde cholangiopancreatography at militar central in Bogota in the period January 2011 to June 2012. Revista Med 2014;22:20-7.

12. Cotton PB, Donald A. Garrow, et al. Risk factors for complications after ERCP: a multivariate analysis of 11.497 procedures over 12 years. Gastrointest Endosc Volume 2009;70:80-8.
13. Fritz E, Kirchgatterer A, Hubner D, et al. ERCP is safe and effective in patients 80 years of age and older compared with younger patients. Gastrointest Endosc 2006;64:899-905.

14. Katsinelos P, Paroutoglou G, Kountouras J, et al. Efficacy and safety of therapeutic ERCP in patients 90 years of age and older. Gastrointest Endosc 2006;63:417-23.

15. Kandemir A, Arabul M, Çelik M, et al. Yaşlı hastalarda gastrointestinal endoskopik işlemlerin değerlendirilmesi. Turkish Journal of Geriatrics 2013;16:43-7.

16. Freeman ML, DiSario JA, Nelson DB, et al. Risk factors for post-ERCP pancreatitis: A prospective, multicenter study. Gastrointest Endosc 2001;54:425-34.

17. Badalov N, Tenner S, Baillie J. The Prevention, recognition and treatment of post-ERCP pancreatitis. JOP 2009; 10:88-97.

18. Cappell MS. Acute pancreatitis: etiology, clinical presentation, diagnosis, and therapy. Med Clin North Am 2008;92:889-923.

19. Cooper ST, Slivka A. Incidence, risk factor, and prevention of post-ERCP pancreatitis. Gastroenterol Clin Nort Am 2007;36:259-76.

20. David Zagalsky, Juan Lasa. Needle-knife fistulotomy and risk of post-ERCP pancreatitis. Gastrointest Endosc 2017;86:247-8. 